\title{
Articles
}

\section{Water and Cation Distribution in Fully and Partially Hydrated Li-LSX Zeolite}

\author{
A. Wozniak, ${ }^{\dagger}$ B. Marler, ${ }^{*}{ }^{\dagger}$ K. Angermund, ${ }^{\star}$ and H. Gies ${ }^{\dagger}$ \\ Institut für Geologie, Mineralogie and Geophysik, Ruhr Universität Bochum, Bochum D-44221, Germany, \\ and Max Planck Institut für Kohlenforschung, Mülheim an der Ruhr D-45470, Germany
}

Received December 21, 2007. Revised Manuscript Received July 18, 2008

\begin{abstract}
Faujasite type zeolite Li-LSX with unit cell composition $\mathrm{Li}_{96}\left[\mathrm{Si}_{96} \mathrm{Al}_{96} \mathrm{O}_{384}\right] \cdot x \mathrm{H}_{2} \mathrm{O}$ is a very promising sorption material for heat storage and energy transformation. To understand the hydration and dehydration processes and to optimize the sorption properties, the structures of partially and fully hydrated Li-LSX with water loadings of $x=8,16,32,48,96$, and $270 \mathrm{H}_{2} \mathrm{O} / \mathrm{D}_{2} \mathrm{O}$ were analyzed based on neutron and synchrotron powder data. In addition, forcefield simulations were performed. At low loading of water the cations occupy three sites: $\mathrm{SI}^{\mathrm{C}}$ (in the center of a 6-ring window of the $\beta$-cage), $\mathrm{SII}^{\mathrm{C}}$ (in the center of another 6-ring window of the $\beta$-cage), and SIII (in front of the 4-ring of the $\beta$-cage). Increasing hydration leads to the disordering of $\mathrm{Li}^{+}$at site SIII, which interacts with water molecules. As a consequence, $\mathrm{Li}^{+}$moves from SIII sites to other crystallographic sites. In total six different crystallographic water sites (W1-W6) were identified. Nearly all water molecules occupy the supercage; 2.3 water molecules (W1) were also located inside the sodalite cage only in the fully hydrated stage.
\end{abstract}

\section{Introduction}

Presently, zeolite/water systems are very promising materials for heat storage and for energy transformation using solar energy as a renewable heat source. The particular property exploited is the reversible hydration/dehydration process. Li-LSX zeolite with chemical composition $\mathrm{Li}_{96}\left[\mathrm{Si}_{96} \mathrm{Al}_{96} \mathrm{O}_{384}\right] \cdot x \mathrm{H}_{2} \mathrm{O}, x \leq 270$, is a particularly interesting sorption material; ${ }^{1}$ however, it is still far from mass application. To optimize the material and to understand the hydration and dehydration processes on the atomistic level, it is necessary to know the detailed structures of partially and fully hydrated Li-LSX zeolites. In the past years the lithium cation distribution of fully dehydrated zeolite $\mathrm{Li}$ LSX has been studied with X-ray and neutron diffraction methods and with nuclear magnetic resonance spectroscopy; ${ }^{2-4}$ however, structures of partially hydrated materials were not elucidated. Li-LSX is low silica $\mathrm{X}$ zeolite with a $\mathrm{Si} / \mathrm{Al}$ ratio of 1. Its framework structure is formed of strictly alternating $\left[\mathrm{SiO}_{4}\right]$ and $\left[\mathrm{AlO}_{4}\right]$ tetrahedra in accordance with the Loewenstein's avoidance rule. The aluminosilicate framework

* Corresponding author. E-mail: bernd.marler@ruhr-uni-bochum.de.

'Ruhr Universität Bochum.

* Max Planck Institut für Kohlenforschung.

(1) Jänchen, J.; Grimm, A.; Stach, H. Proceedings of the 13th International Zeolite Conference; Studies in Surface Science and Catalysis; Elsevier: New York, 2001; Vol. 135.

(2) Herden, H.; Einicke, W. D.; Schollner, R.; Mortier, W. J.; Gellens, L. R.; Uytterhoeven, J. B.; et al. Zeolites 1982, 2, 131-134.

(3) Forano, R. C.; Slade, T.; Krogh Andersen, I. G.; Prince, E. J. Solid State Chem. 1989, 82, 95-102.

(4) Feuerstein, M.; Lobo, R. F. Chem. Mater. 1998, 10, 2197-2204.

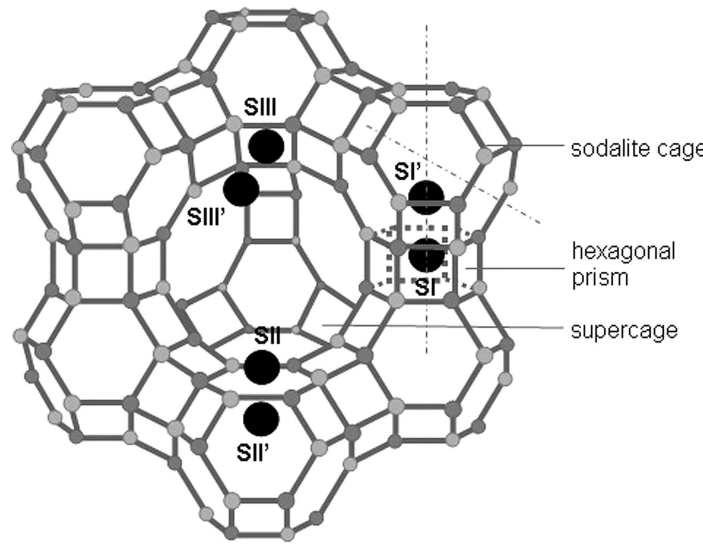

Figure 1. Cation sites with nomenclature and cation distribution in dehydrated FAU type zeolite.

consists of three types of building units: hexagonal prisms, sodalite- or $\beta$-cages with a diameter of $\sim 8 \AA$, and super- or $\alpha$-cages with a diameter of $\sim 12 \AA$ (see Figure 1 ). In one unit cell of this zeolite consisting of eight sodalite cages and eight supercages about 260-280 water molecules can be accommodated. The zeolite has the Faujasite (FAU) framework type ${ }^{5}$ with cubic symmetry. Generally, cations can occupy up to 6 different sites in FAU type zeolites (Figure 1). While site SI is located in the hexagonal prism, site SI' is situated close to the hexagonal prism but slightly shifted into the sodalite cage. Sites SII and SII' are placed close to

(5) Baerlocher, Ch.; Meier, W. M.; Olson, D. H. Atlas of Zeolite Framework Types, 5th ed.; Elsevier: Amsterdam, 2001. 
the hexagonal ring which interconnects the sodalite and the super cage with SII shifted into the super cage and SII' located inside the sodalite cage. The positions SIII and SIII' are both inside the supercage. While SIII is ascribed to a central position in front of the 4-ring of the $\beta$-cage, SIII' is near to the edge of this 4-ring but can as well be described as being located in the plane of the 12-ring (Figure 1). On the basis of previous studies, ${ }^{6}$ it is recognized that the cations in the dehydrated Li-LSX are distributed between three or four extraframework sites: Favored are especially the sites close to 6-membered rings (6MR) of the framework ( $\mathrm{SI}^{\prime}$, SII). These two sites have a multiplicity of 32 . Generally, in the dehydrated form of Li-LSX, these sites are fully occupied. The remaining 32 cations were not easy to locate. Plevert et al. ${ }^{6}$ found these cations being equally distributed between sites SIII and SIII'. Feuerstein and Lobo who also studied the dehydrated form of Li-LSX observed a part of the remaining $\mathrm{Li}^{+}$on SIII but did not find $\mathrm{Li}^{+}$on site SIII'. On the basis of variable temperature MAS NMR spectroscopy they witnessed high mobility of $\mathrm{Li}^{+}$on site SIII which increased with the temperature.

In our contribution, the structure of partially hydrated LiLSX $\left(\mathrm{Li}_{96}\left[\mathrm{Si}_{96} \mathrm{Al}_{96} \mathrm{O}_{384}\right] \cdot x \mathrm{D}_{2} \mathrm{O} / \mathrm{H}_{2} \mathrm{O}\right)$ with water loading of $x=8,16,32,48,96$, and 270 was analyzed using neutron and synchrotron powder diffraction data. In addition forcefield calculations were performed giving a most complete picture of the structure of dehydrated, partially hydrated, and fully hydrated Li-LSX.

\section{Experimental Section}

Samples. In the present study Li-LSX zeolite was used, which is a commercially available, binder-free material produced by Süd - Chemie AG. For neutron diffraction experiments five samples with different water loading $\left(8,16,32,48\right.$, and $96 \mathrm{D}_{2} \mathrm{O}$ per unit cell) were prepared. Before the defined amount of $\mathrm{D}_{2} \mathrm{O}$ was added, the Li-LSX was dried under high vacuum at $673 \mathrm{~K}$ for $48 \mathrm{~h}$. To attain homogeneity, partially hydrated samples were heated for $24 \mathrm{~h}$ at $353 \mathrm{~K}$. After the neutron experiments, $\mathrm{D}_{2} \mathrm{O}$ content of all samples was verified using nuclear magnetic resonance spectroscopy. For the synchrotron diffraction experiment a fully hydrated Li-LSX sample was used.

Neutron Diffraction. Neutron diffraction data of all samples were recorded at $200 \mathrm{~K}$ with neutron wavelength of $\lambda=2.397 \AA$ in the range of $0^{\circ}$ to $180^{\circ}$ in $2 \theta$ on D2B at the ILL in Grenoble. ${ }^{7}$ Structures were refined using the Rietveld method $^{8}$ with the FullProf suite of programs. ${ }^{9}$ A Thompson-Cox-Hastings pseudo-Voigt profile function with axial divergence asymmetry function ${ }^{10}$ was used to model the peaks. The diffraction data of all samples were refined in space group $F d \overline{3}$, since there was no indication of lower symmetry (e.g., additional lines, peak splitting, etc.) in any of the powder patterns.

In a first step of the refinement, profile parameters, background parameters, unit cell constant, and zero-point were optimized. The

(6) Plevert, J.; Di Renzo, F.; Fajula, F.; Chiari, G. J. Phys. Chem. B 1997, $101,10340-10346$

(7) http://www.ill.fr/index_sc.html (accessed December 2007).

(8) Rietveld, H. M. J. Appl. Crystallogr. 1969, 2, 65-71.

(9) Roisnel, T.; Rodríguez-Carvajal, J. Materials Science Forum. Proceedings of the Seventh European Powder Diffraction Conference (EPDIC 7); Trans Tech Publications: Stafa-Zurich, Switzerland, 2001; Vols. 378-381; pp 118-123.

(10) Finger, J.; Cox, D. E. J. Appl. Crystallogr. 1994, 27, 892-900. initial positions of the framework atoms were taken from the dehydrated Li-LSX structure. ${ }^{11}$

The positions of the framework atoms were refined applying 24 distance restraints $(\mathrm{Si}-\mathrm{O}=1.64 \AA, \mathrm{Al}-\mathrm{O}=1.73 \AA$, $\mathrm{Si}-\mathrm{Al}=$ $3.10 \AA, \mathrm{O}-\mathrm{O}=2.72 \AA$ ). The framework structure of zeolite LSX is well-known with defined atomic distances which vary only slightly with the water and cation content. These restraints are helpful to obtain a stable refinement. In contrast, no geometric restraints have been applied for the refinement of the oxygen atoms representing the $\mathrm{D}_{2} \mathrm{O} / \mathrm{H}_{2} \mathrm{O}$ molecules and the lithium cations at sites SI'and SII. This was done to avoid the effect that the refined positions of the water molecules and those lithium cations are biased by prescribed values. The only additional restraint necessary was the one between the highly disordered Li cation at site SIII and the oxygen atom $\mathrm{O} 4(\mathrm{Li}-\mathrm{O}=2.00 \AA)$. Thus, a total of 25 restraints were applied. The nonframework species (exept for Li at SIII) were allowed to take any position in the structure and to have any distance to other atoms when refining the structure model against the experimental data.

Water molecules are visible in Fourier maps as maxima including the scattering contribution of the oxygen and deuterium atoms. To obtain realistic occupancy factors for water molecules at each hydration stage, displacement (temperature) factors of water sites were kept fixed at crystal chemically meaningful values during the refinement. In the course of the refinement it proved to be impossible to distinguish between oxygen and deuterium atoms of the water molecules. This can be explained by fast rotation of the $\mathrm{D}_{2} \mathrm{O}$ molecule. The $\mathrm{D}_{2} \mathrm{O}$ molecules were, therefore, represented by oxygen atoms with a rather high displacement parameter. As a consequence, the refined occupancy factors represent only a relative measure of the number of water molecules at the particular site.

Synchrotron Diffraction. Synchrotron diffraction data of fully hydrated Li-LSX were collected at $295 \mathrm{~K}$ with X-ray wavelength of $\lambda=0.698081 \AA$ on beam line B2 at HASYLAB in Hamburg. Details of the instrumental setup are available elsewhere. ${ }^{12}$ The diffraction pattern of the samples was analyzed using the same software and applying the same strategy as described above for the neutron data.

Computational Details of the Forcefield Simulations. Calculations were performed using InsightII v.4.0.0 and Discover $3^{13}$ on a SGI Octane. On the basis of the result of a Rietveld refinement (Chapter 3) a periodical model of the crystal (one unit cell, edge size $24.6713 \AA$, with internal symmetry $P 1$ ) consisting of 576 framework atoms and 96 lithium cations was constructed. In all subsequent calculations the framework atoms were kept fixed. The CVFF force field ${ }^{13}$ and an atom based cutoff radius of $20 \AA$ for all nonbond interactions were applied.

\section{Results and Discussion}

3.1. Neutron Diffraction Study of the Crystal Structure of Partially Hydrated Li-LSX. The results of the final Rietveld refinements together with all relevant crystallographic data are summarized in Table 1. The positions of framework atoms changed very little with the water content of the sample; therefore, only the atomic coordinates of the framework atoms of Li-LSX $\cdot 8 \mathrm{D}_{2} \mathrm{O}$ are summarized in Table 2 as an example.

(11) Fridriksson, T.; Bish, D. L.; Bird, D. K. Am. Mineral. 2003, 88, 277287.

(12) http://hasylab.desy.de/user_info/available_instruments/x_ray_diffraction imaging/b2/index_eng.html (accessed March 2007).

(13) Discover User Guide, Part 1; BioSym Technology: San Diego, May 1995. 
Table 1. Experimental and Crystallographic Parameters for the Structure Refinement of Li-LSX at Different Hydration Stages

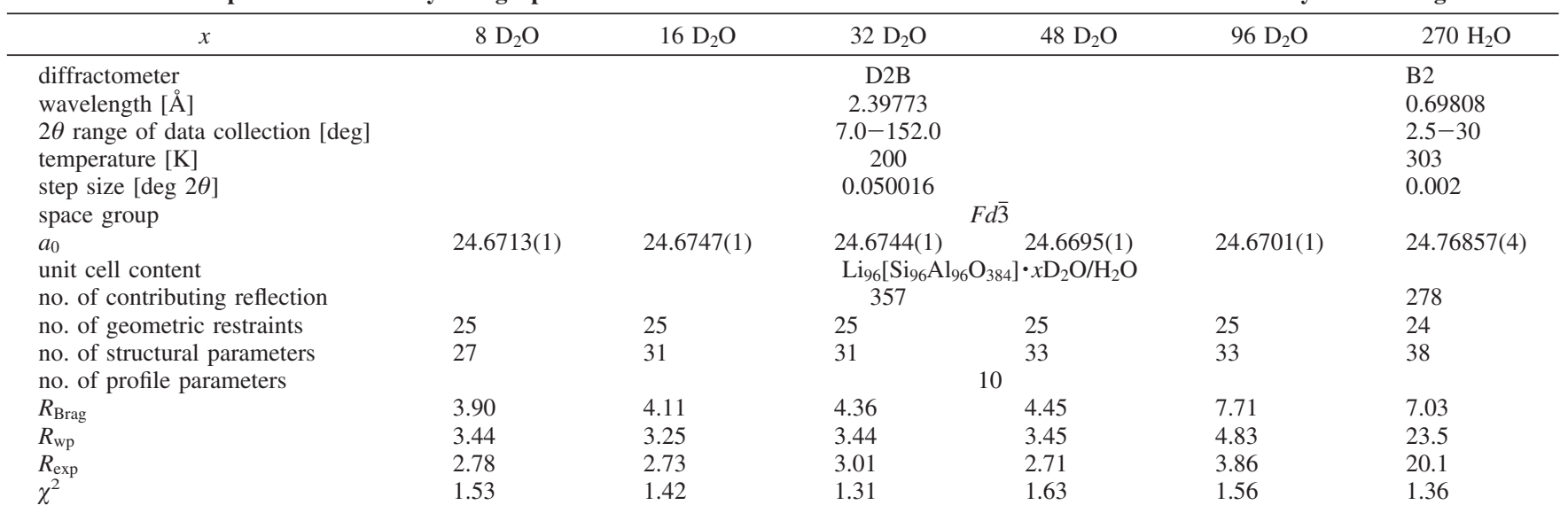

Table 2. Neutron Diffraction Refinement at $200 \mathrm{~K}^{a}$

\begin{tabular}{lcrrrrrr}
\hline & & \multicolumn{3}{c}{ framework of Li-LSX } & \\
\cline { 2 - 5 } atom & $x$ & $y$ & $z$ & SOF & Biso & multiplicity of site & number of atoms/unit cell \\
\hline Si1 & $-0.0499(5)$ & $0.1250(5)$ & $0.0355(5)$ & 1.0 & 1.3 & 96 & 96 \\
A11 & $-0.0478(5)$ & $0.0390(6)$ & $0.1232(5)$ & 1.0 & 1.3 & 96 & 96 \\
O1 & $-0.1027(5)$ & $0.0037(9)$ & $0.0991(5)$ & 1.0 & 2.7 & 96 & 96 \\
O2 & $-0.0006(5)$ & $-0.0019(5)$ & $0.1533(4)$ & 1.0 & 2.7 & 96 & 96 \\
O3 & $-0.0217(3)$ & $0.0742(5)$ & $0.0686(4)$ & 1.0 & 2.7 & 96 & 96 \\
O4 & $-0.0735(4)$ & $0.0814(5)$ & $0.1713(4)$ & 1.0 & 2.7 & 96
\end{tabular}

${ }^{a}$ Optimized atomic coordinates, site occupancy factors, displacement parameters, multiplicity of sites, and number of atoms in occupied site per unit cell for framework of Li-LSX at low water loading $\left(8 \mathrm{H}_{2} \mathrm{O}\right.$ per unit cell).

Before discussing partially hydrated Li-LSX, it is instructive to take a look on the structure of dehydrated Li-LSX. Lithium cations are distributed over three symmetrically different sites (Table 3). They are all in close vicinity of the small sodalite cage and correspond to the known sites $\mathrm{SI}^{\prime}$, SII, and SIII. ${ }^{4}$ The $\mathrm{Li}^{+}$cations of the first two sites are both 3-coordinated by framework oxygen atoms with bond lengths of approximately $1.89 \AA$ and $1.97 \AA$, respectively (Table 4). The distances are very close to the sum of the ionic radii $\left(r_{\mathrm{Li}}=0.59 \AA, r_{\mathrm{O}}=1.36 \AA\right)$. Since these $\mathrm{Li}^{+}$cations are located nearly exactly in the center of the 6MR, they have highly symmetric coordination (center of a regular triangle). Most of the remaining $32 \mathrm{Li}^{+}$cations are positioned on site SIII (multiplicity of 48) in front of the 4MR of the sodalite cage. These $\mathrm{Li}^{+}$cations are only 2-coordinated by framework oxygen atoms with bond lengths of approximately $2.1 \AA$. The coordination "polyhedron" is extremely asymmetric with $\mathrm{Li}(\mathrm{SIII})$ occupying a corner of a triangle. It is to be expected that the $\mathrm{Li}^{+}$cations on SIII try to "change their position/ coordination" if water is added.

Compared to a neutral $\mathrm{SiO}_{2}$ framework, the framework of a LSX zeolite, with composition $\left[\mathrm{AlSiO}_{4}\right]$, possesses a negative charge since the charge of the $\mathrm{O}^{2-}$ ions are only partly compensated by $\mathrm{Si}^{4+}$ and $\mathrm{Al}^{3+}$ ions. Formally each oxygen carries a residual charge of -0.25 which attracts cations (e.g., $\mathrm{Li}^{+}$) and dipoles (e.g., $\mathrm{H}_{2} \mathrm{O} / \mathrm{D}_{2} \mathrm{O}$ ). Dehydrated Li-LSX with composition $\mathrm{Li}\left[\mathrm{AlSiO}_{4}\right]$ possesses 4 symmetrically distinct oxygen sites which differ with respect to the presence or absence of ionic bonds to $\mathrm{Li}^{+}$cations: $\mathrm{O} 2$ in the $6 \mathrm{MR}$ has an anionic bond to $\mathrm{Li}\left(\mathrm{SII}^{\mathrm{C}}\right)$; thus, the residual charge is counter balanced. The same is true for $\mathrm{O} 3$ which has an anionic bond to $\mathrm{Li}\left(\mathrm{SI}^{\mathrm{C}}\right)$. $\mathrm{O} 1$ being part of the $4 \mathrm{MR}$ of the hexagonal prism has no ionic bond to a lithium cation, and the residual charge of the oxygen is not compensated at a short distance. O4 is part of the 4MR of the sodalite cage; 48 of these 4MR exist per unit cell. In this case two different situations have to be distinguished. Since there is only a maximum of $32 \mathrm{Li}$ cations which can occupy the SIII site in front of the 4MR at least sixteen 4MR are left without the $\mathrm{Li}^{+}$cation. If we look at these "Li-free" $4 \mathrm{MR}$ in the framework structure (Figure 2) it is obvious that there is a cluster of residual (negative) charge in close vicinity of the $4 \mathrm{MR}$ of the sodalite cage.

Structure of $\operatorname{Li}-\mathrm{LSX} \cdot 8 \mathrm{D}_{2} \mathrm{O}$. The result of the refinement of the neutron powder diffraction data at very low water loading $\left(8 \mathrm{D}_{2} \mathrm{O}\right.$ per unit cell) of zeolite Li-LSX at $200 \mathrm{~K}$ is shown in Figure 3. The agreement of the structural model and the experimental data is very good $\left(R_{\mathrm{Bragg}}=3.90, R_{\mathrm{wp}}\right.$ $\left.=3.44, R_{\mathrm{p}}=2.78, \chi^{2}=1.53\right)$. The lithium cations are distributed over the three sites mentioned above (Table 3 ).

To emphasize the fact that the first two sites are located nearly exactly in the center of the 6- ring windows of the sodalite cage we named these sites in the following: $\mathrm{SI}^{\mathrm{C}}$ and $\mathrm{SII}^{\mathrm{C}}(\mathrm{C}=$ center$)$. The $\mathrm{Li}^{+}$cations at these sites are both 3-coordinated by framework oxygen atoms with bond lengths of $1.89 \AA$ and $1.99 \AA$, respectively (see Table 4 ). $\mathrm{SI}^{\mathrm{C}}$ and $\mathrm{SII}^{\mathrm{C}}$ have a multiplicity of 32 and are fully occupied. Seventeen of the remaining $32 \mathrm{Li}^{+}$cations are positioned on site SIII in front of the 4MR of the sodalite cage (see Table 3 and Figure 4) forming two bonds to framework oxygen atoms O4 with a length of 2.01(6) ̊̊.

The position of the remaining $15 \mathrm{Li}^{+}$could not be located. Our result is close to the one reported by Feuerstein at al. but in contrast to Plevert at al. since no $\mathrm{Li}^{+}$was found on SIII'. 
Table 3. Neutron Diffraction Refinement at $200 \mathrm{~K}^{a}$

\begin{tabular}{|c|c|c|c|c|c|c|c|}
\hline atom & $x$ & $y$ & $z$ & SOF & Biso & multiplicity of site & number of atoms/unit cell \\
\hline \multicolumn{8}{|c|}{8 Water Molecules per Unit Cell } \\
\hline $\mathrm{Li}^{+}\left(\mathrm{SI}^{\mathrm{C}}\right)$ & $0.046(1)$ & $0.046(1)$ & $0.046(1)$ & 0.33333 & 2.5 & 32 & 32 \\
\hline $\mathrm{Li}^{+}\left(\mathrm{SII}^{\mathrm{C}}\right)$ & $0.223(1)$ & $0.223(1)$ & $0.223(1)$ & 0.33333 & 2.5 & 32 & 32 \\
\hline W3 & $0.119(7)$ & $-0.220(4)$ & $0.170(5)$ & $0.15(2)^{b}$ & 20 & 96 & 8 \\
\hline $\begin{array}{l}\mathrm{Li}^{+}\left(\mathrm{SI}^{\mathrm{C}}\right) \\
\mathrm{Li}^{+}\left(\mathrm{SII}^{\mathrm{C}}\right) \\
\mathrm{Li}^{+}(\mathrm{SIII}) \\
\mathrm{W} 3 \\
\mathrm{~W} 4\end{array}$ & $\begin{array}{l}0.047(1) \\
0.224(1) \\
0.125 \\
0.133(5) \\
0.593(6)\end{array}$ & $\begin{array}{r}0.047(1) \\
0.224(1) \\
-0.125(1) \\
-0.208(3) \\
0.520(7)\end{array}$ & $\begin{array}{l}\quad 16 \\
0.047(1) \\
0.224(1) \\
0.125 \\
0.160(4) \\
0.467(6)\end{array}$ & $\begin{array}{c}\text { Molecules } \\
0.33333 \\
0.33333 \\
0.15(4) \\
0.22(2)^{b} \\
0.12(2)^{b}\end{array}$ & $\begin{array}{c}\text { Unit C } \\
2.5 \\
2.5 \\
10 \\
20 \\
20\end{array}$ & $\begin{array}{l}32 \\
32 \\
48 \\
96 \\
96\end{array}$ & $\begin{array}{r}32 \\
32 \\
14 \\
10 \\
6\end{array}$ \\
\hline \multicolumn{8}{|c|}{32 Water Molecules per Unit Cell } \\
\hline $\mathrm{Li}^{+}\left(\mathrm{SI}^{\mathrm{C}}\right)$ & $0.047(1)$ & $0.047(1)$ & $0.047(1)$ & 0.33333 & 2.5 & 32 & 32 \\
\hline $\mathrm{Li}^{+}\left(\mathrm{SII}^{\mathrm{C}}\right)$ & $0.223(1)$ & $0.223(1)$ & $0.223(1)$ & 0.33333 & 2.5 & 32 & 32 \\
\hline $\mathrm{Li}^{+}(\mathrm{SIII})$ & 0.125 & $-0.127(3)$ & 0.125 & $0.11(4)$ & 10 & 48 & 11 \\
\hline W3 & $0.108(7)$ & $-0.206(3)$ & $0.154(6)$ & $0.27(2)^{b}$ & 20 & 96 & 18 \\
\hline \multicolumn{8}{|c|}{48 Water Molecules per Unit Cell } \\
\hline $\mathrm{Li}^{+}(\mathrm{SIII})$ & 0.125 & $-0.126(4)$ & 0.125 & $0.11(4)$ & 10 & 48 & 11 \\
\hline W3 & $0.105(9)$ & $-0.202(3)$ & $0.153(8)$ & $0.29(2)^{b}$ & 20 & 96 & 20 \\
\hline W4 & $0.627(3)$ & $0.501(4)$ & $0.485(4)$ & $0.30(2)^{b}$ & 20 & 96 & 21 \\
\hline W2 & $0.279(3)$ & $0.279(3)$ & $0.279(3)$ & $0.11(1)^{b}$ & 20 & 32 & 7 \\
\hline \multicolumn{8}{|c|}{96 Water Molecules per Unit Cell } \\
\hline $\mathrm{Li}^{+}\left(\mathrm{SI}^{\mathrm{C}}\right)$ & $0.049(2)$ & $0.049(2)$ & $0.049(2)$ & 0.3333 & 2.5 & 32 & 32 \\
\hline $\mathrm{Li}^{+}\left(\mathrm{SIII}^{\mathrm{C}}\right)$ & $0.229(2)$ & $0.229(2)$ & $0.229(2)$ & 0.3333 & 2.5 & 32 & 32 \\
\hline $\mathrm{Li}^{+}(\mathrm{SIII})$ & 0.125 & $-0.121(4)$ & 0.125 & $0.08(7)$ & 10 & 48 & 8 \\
\hline W3 & $0.166(5)$ & $-0.193(5)$ & $0.135(5)$ & $0.37(3)^{b}$ & 20 & 96 & 31 \\
\hline W4 & $0.604(3)$ & $0.524(3)$ & $0.473(3)$ & $0.48(3)^{b}$ & 20 & 96 & 41 \\
\hline W2 & $0.281(2)$ & $0.281(2)$ & $0.281(2)$ & $0.28(2)^{b}$ & 20 & 32 & 24 \\
\hline
\end{tabular}

${ }^{a}$ Optimized atomic coordinates, occupancy factors, displacement parameters, multiplicity of sites, and number of atoms in occupied site per unit cell for cations and water molecules at different hydration grade of Li-LSX. ${ }^{b}$ The number of water molecules for a given water site was calculated according to the SOF with the total number of molecules per unit cell being normated to the amount of water added to the zeolite material.

Table 4. Interatomic Distances at Different Hydrated Li-LSX from Neutron Diffraction and Synchrotron Refinement

\begin{tabular}{|c|c|c|c|c|c|c|}
\hline \multirow[b]{2}{*}{ distance $(\AA)$} & \multicolumn{6}{|c|}{ different hydration stage } \\
\hline & $8 \mathrm{D}_{2} \mathrm{O}$ & $16 \mathrm{D}_{2} \mathrm{O}$ & $32 \mathrm{D}_{2} \mathrm{O}$ & $48 \mathrm{D}_{2} \mathrm{O}$ & $96 \mathrm{D}_{2} \mathrm{O}$ & $270 \mathrm{H}_{2} \mathrm{O}$ \\
\hline $\mathrm{Li}^{+}\left(\mathrm{SI}^{\mathrm{C}}\right)-\mathrm{O} 3$ & $1.89(3)$ & $1.92(2)$ & $1.90(3)$ & $1.91(3)$ & $1.92(4)$ & $1.94(6)$ \\
\hline $\mathrm{Li}^{+}\left(\mathrm{SII}^{\mathrm{C}}\right)-\mathrm{O} 2$ & $1.99(3)$ & $2.00(2)$ & $1.99(3)$ & $1.98(3)$ & $2.02(4)$ & $2.11(6)$ \\
\hline $\mathrm{Li}^{+}(\mathrm{SIII})-\mathrm{O} 4$ & $2.01(6)$ & $2.01(6)$ & $2.03(6)$ & $2.02(6)$ & $2.01(6)$ & \\
\hline W3- $\mathrm{Li}^{+}(\mathrm{SIII})$ & $2.6(1)$ & $2.2(1)$ & $2.1(1)$ & $2.0(1)$ & $2.1(1)$ & \\
\hline W3-W3 & $2.2(2)$ & $1.8(1)$ & $1.7(2)$ & $1.7(3)$ & $2.1(2)$ & $2.19(7)$ \\
\hline W3-O1 & $3.5(1)$ & $3.4(1)$ & $3.6(1)$ & $3.5(1)$ & $3.2(1)$ & $3.25(4)$ \\
\hline W3-O4 & $3.8(1)$ & $3.6(1)$ & $3.34(8)$ & $3.21(8)$ & $3.3(1)$ & $3.59(4)$ \\
\hline W4-O4 & & $3.4(2)$ & $2.8(1)$ & $2.8(1)$ & $3.34(8)$ & $2.84(4)$ \\
\hline W4-O1 & & $3.3(2)$ & $3.4(1)$ & $3.4(1)$ & $3.33(8)$ & $2.83(6)$ \\
\hline \multirow[t]{2}{*}{ W4-W3 } & & $2.8(2)$ & $2.8(2)$ & $2.8(1)$ & $1.8(1)$ & $3.21(6)$ \\
\hline & & $2.9(2)$ & $3.1(2)$ & $3.1(2)$ & $3.6(1)$ & $3.45(6)$ \\
\hline $\mathrm{W} 2-\mathrm{O} 2$ & & & & $3.25(8)$ & $3.35(4)$ & $3.20(3)$ \\
\hline W2-W3 & & & & $>3.8$ & $3.3(1)$ & $3.10(5)$ \\
\hline W2-W4 & & & & $2.6(1)$ & $3.2(1)$ & $3.56(4)$ \\
\hline $\mathrm{W} 2-\mathrm{Li}^{+}\left(\mathrm{SII}^{\mathrm{C}}\right)$ & & & & $2.38(8)$ & $2.25(6)$ & $1.84(6)$ \\
\hline $\mathrm{W} 1-\mathrm{Li}^{+}\left(\mathrm{SI}^{\mathrm{C}}\right)$ & & & & & & $2.08(8)$ \\
\hline $\mathrm{W} 1-\mathrm{O} 3$ & & & & & & $2.92(6)$ \\
\hline W5-W4 & & & & & & $2.96(6)$ \\
\hline W5-W3 & & & & & & $3.26(6)$ \\
\hline W5-W6 & & & & & & $3.04(5)$ \\
\hline
\end{tabular}

The adsorbed water molecules $\left(8 \mathrm{D}_{2} \mathrm{O}\right.$ per unit cell) which are the very first of 270 possible molecules occupy the water site $\mathrm{W} 3$ which is situated close to $\mathrm{Li}^{+}$at SIII with a $\mathrm{Li}-\mathrm{W} 3$ distance of 2.6 (1) $\AA$ (Figure 4). The shortest distance between W3 and an oxygen atom of the framework is $3.5 \AA$ indicating that there are only very weak interactions between the water molecule and the framework. The $\mathrm{W} 3$ position is only partially occupied with a site occupancy factor (SOF) of 0.15 . Because of the high mobility of the water molecules the refined SOF value gives only a relative measure of the water occupancy on this site. Since in this case no other water position was observed we assigned all $\mathrm{D}_{2} \mathrm{O}$ to this site (a water amount corresponding to $8 \mathrm{D}_{2} \mathrm{O}$ per unit cell had been added to the dry sample). The W3 site is formally a general position with a multiplicity of 96 molecules per unit cell. The distance between two neighboring, symmetry related water molecules (W3 and W3') is calculated to $2.2 \AA$. It is not possible to decide whether only one or both of the two neighboring sites are in fact occupied by a water molecule.

Since there are only $8 \mathrm{D}_{2} \mathrm{O}$ but $17 \mathrm{Li}(\mathrm{SIII})$ we assume that in fact 8 of the $17 \mathrm{Li}^{+}$observed on SIII (in front of the $4 \mathrm{MR}$ ) are coordinated by three oxygen atoms (two framework atoms and one water) forming a distorted triangle. The other $9 \mathrm{Li}^{+}$are still "naked" with a rather asymmetric coordination by only two framework oxygen atoms. It has

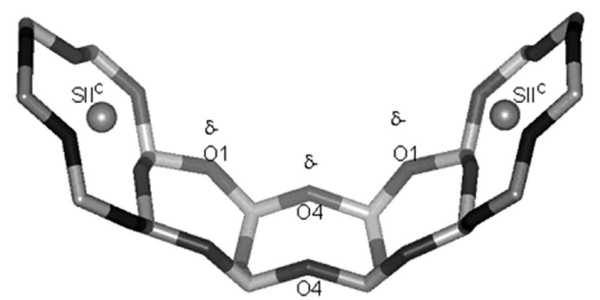

Figure 2. Section of the structure of Li-LSX showing the residual charge in the close vicinity of a "Li-free" $4 \mathrm{MR}$ of the sodalite cage. 


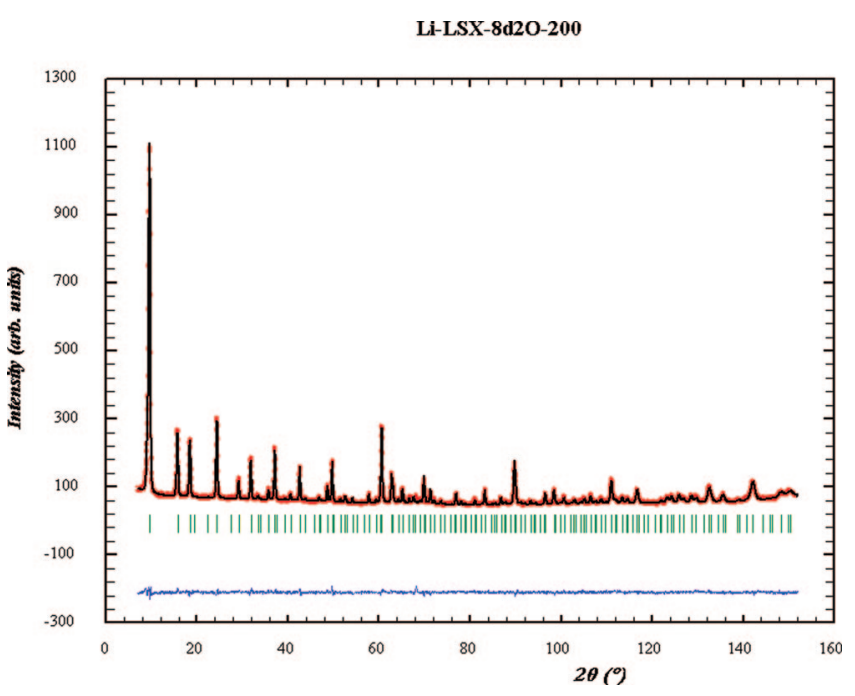

Figure 3. Neutron powder pattern and Rietveld plot for the refinement of zeolite Li-LSX with $8 \mathrm{D}_{2} \mathrm{O}$ per unit cell. Upper part: the experimental data (red), calculated profile (black), and Bragg peaks (green). Lower part: difference between experimental and calculated profile.

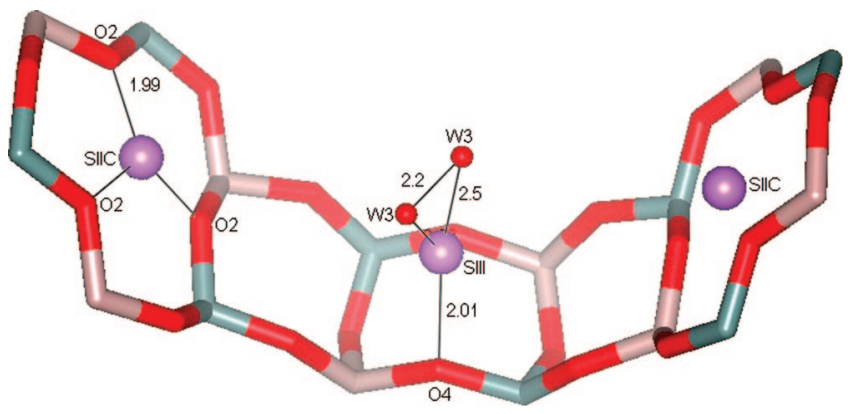

Figure 4. Lithium cations at sites $\mathrm{SII}^{\mathrm{C}}$ and $\mathrm{SIII}$ and the first adsorbed water molecule at site $\mathrm{W} 3$ at low hydration of Li-LSX zeolite $\left(8 \mathrm{D}_{2} \mathrm{O}\right)$.

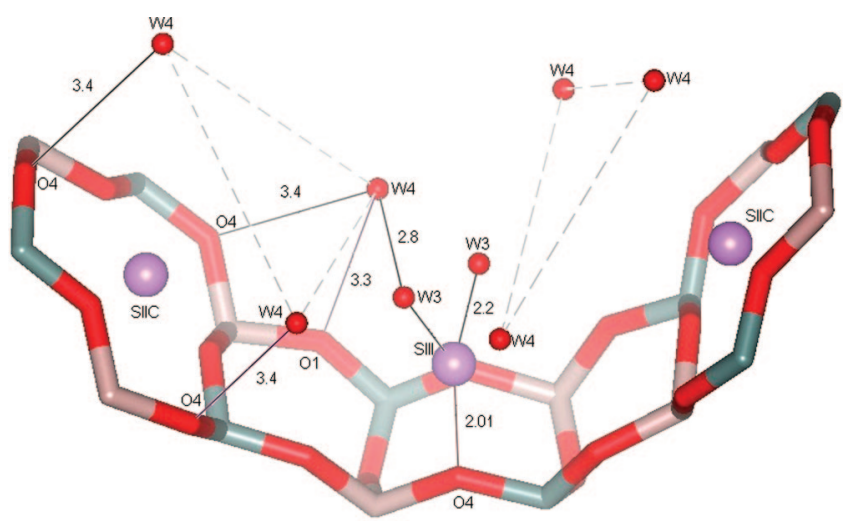

Figure 5. Positions of the lithium cations (sites $\mathrm{SII}^{\mathrm{C}}$ and SIII) and the water molecules (sites W3 and W4) for Li-LSX with 16 water molecules per unit cell.

to be remembered that this structure analysis gives only an average position for all $\mathrm{Li}^{+}$on SIII whether they are coordinated by a water molecule or not.

Structure of $\mathrm{Li}-\mathrm{LSX} \cdot 16 \mathrm{D}_{2} \mathrm{O}$. Increasing the water loading to $16 \mathrm{D}_{2} \mathrm{O}$, the site occupancy factor of $\mathrm{W} 3$ increases to 0.22 $\left(=10 \mathrm{D}_{2} \mathrm{O}\right.$ per unit cell). The distance between two neighboring, symmetry related $\mathrm{W} 3$ positions is calculated as approximately $1.8 \AA$ A. Additionally, a new water position W4 (Figure 5) was observed which was only partially occupied ( $\mathrm{SOF}=0.12$ corresponding to $6 \mathrm{D}_{2} \mathrm{O}$ per unit cell).

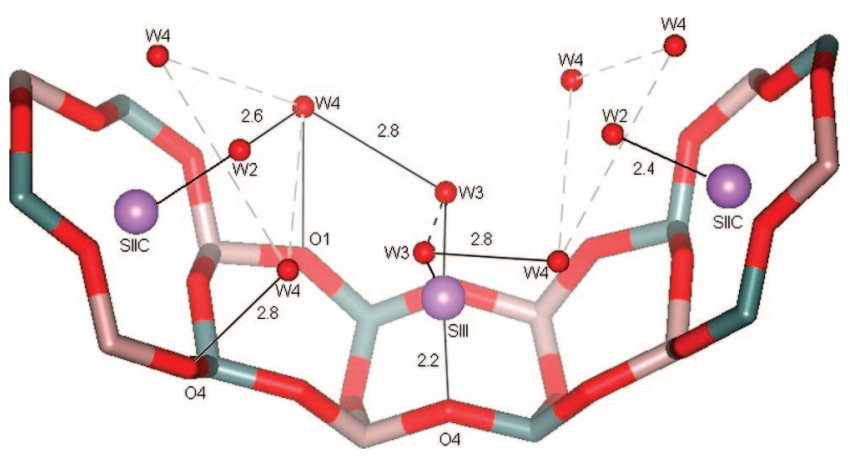

Figure 6. Distribution of water sites at loading of $48 \mathrm{D}_{2} \mathrm{O}$ in Li-LSX.

This site is located in the super cage and has distances of 2.8 and $2.9 \AA$ to W3 indicating hydrogen bridges. There are no interactions of W4 with any of the observed other $\mathrm{Li}^{+}$ cations (W4- $\mathrm{Li}^{+} \geq 3.4 \AA$ ) or with framework atoms (W4- $\mathrm{O}_{\text {framework }} \geq 3.3 \AA$ ).

The lithium populations at sites $\mathrm{SI}^{\mathrm{C}}$ and $\mathrm{SII}^{\mathrm{C}}$ are unchanged $\left(32 \mathrm{Li}^{+}\right.$per unit cell each) while the population of SIII decreases to $14 \mathrm{Li}^{+}$per unit cell. The remaining $18 \mathrm{Li}^{+}$ cations could not be located. It seems possible that these missing $\mathrm{Li}^{+}$are in contact with the $\mathrm{W} 4$ water molecules.

Structure of $L i-L S X \cdot 32 D_{2} O$. After loading the zeolite with 32 water molecules per unit cell the site occupancies of the W3 and W4 positions increased further (see Table 3). Again the lithium populations at sites $\mathrm{SI}^{\mathrm{C}}$ and $\mathrm{SII}^{\mathrm{C}}$ are unchanged (32 $\mathrm{Li}^{+}$per unit cell each) while the number of $\mathrm{Li}^{+}$cations on SIII decreased to 11. With this water content, we observe only $11 \mathrm{Li}^{+}$cations on SIII but $18 \mathrm{D}_{2} \mathrm{O}$ molecules at site W3. Neighboring, symmetry related water molecules have a distance of $1.7 \AA$ indicating that only one of the two (hypothetically) neighboring molecules can in fact be present. This means that each $\mathrm{Li}^{+}$(SIII) is coordinated by only one water molecule and, consequently, at least half of the W3 molecules are not bonded to $\mathrm{a} \mathrm{Li}^{+}$(SIII). It is not possible to distinguish between the $\mathrm{D}_{2} \mathrm{O}$ molecules at site $\mathrm{W} 3$ being attached to $\mathrm{Li}^{+}$(SIII) (a maximum of 11) and the $\mathrm{D}_{2} \mathrm{O}$ molecules occupying a W3 site with no $\mathrm{Li}^{+}$(SIII) being present. The distance between $\mathrm{W} 3$ and framework oxygens is $\geq 3.3 \AA$, indicating extremely weak interactions. We will discuss this fact in the conclusions section.

Structure of $\mathrm{Li}-\mathrm{LSX} \cdot 48 \mathrm{D}_{2} \mathrm{O}$. In the next hydration stage (48 $\mathrm{D}_{2} \mathrm{O}$ per unit cell) one additional site for water, W2, was observed (Figure 6) which coordinates the $\mathrm{Li}^{+}\left(\mathrm{SII}^{\mathrm{C}}\right)$ at a quite large distance of $2.38 \AA$. The distance between W4 and $\mathrm{W} 2$ is $2.6 \AA$. The occupancy factor of $\mathrm{Li}^{+}$(SIII) is 0.11 $\left(=11 \mathrm{Li}^{+}\right.$per unit cell). Disordering of these cationic sites in the structure caused a weak coordination (with only two oxygen atoms of the framework) and strong interaction with water molecules. Such behavior of $\mathrm{Li}^{+}$indicates the presence of more than three cation sites in the structure different from the dehydrated structure.

Structure of $\mathrm{Li}-\mathrm{LSX} \cdot 96 \mathrm{D}_{2} \mathrm{O}$. Further loading the zeolite with water up to $96 \mathrm{D}_{2} \mathrm{O}$ per unit cell leads to an increase of the occupancy factors of the existing water sites W2, W3, and W4 (Figure 7). Despite the rather high loading, the W3 position is still only partially occupied (31 of 48 possible molecules). W3 has probably to be regarded as a split position $\left(d_{\mathrm{W} 3-\mathrm{W} 3}=2.1 \AA\right)$ with $\mathrm{D}_{2} \mathrm{O}$ molecules statistically 


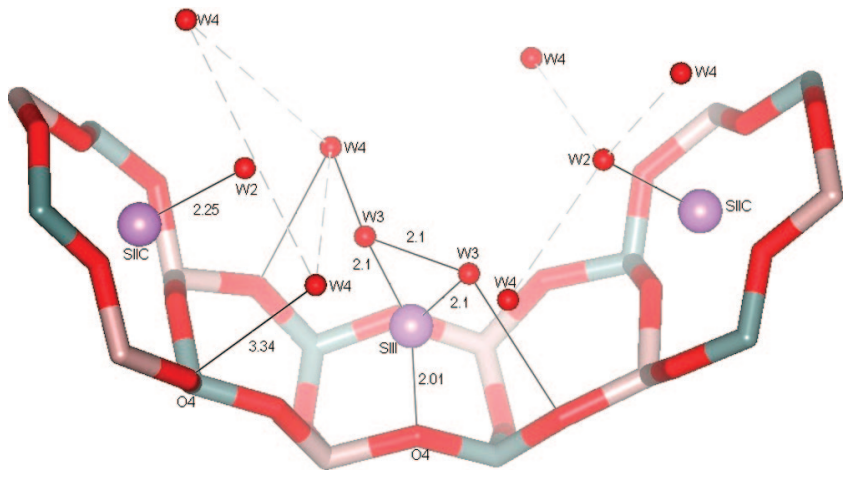

Figure 7. Distribution of water sites at loading of $96 \mathrm{D}_{2} \mathrm{O}$.

Li-LSX $260 \mathrm{H} 2022^{\circ} \mathrm{C}$, Hasylab, $0.698081 \mathrm{~A}$

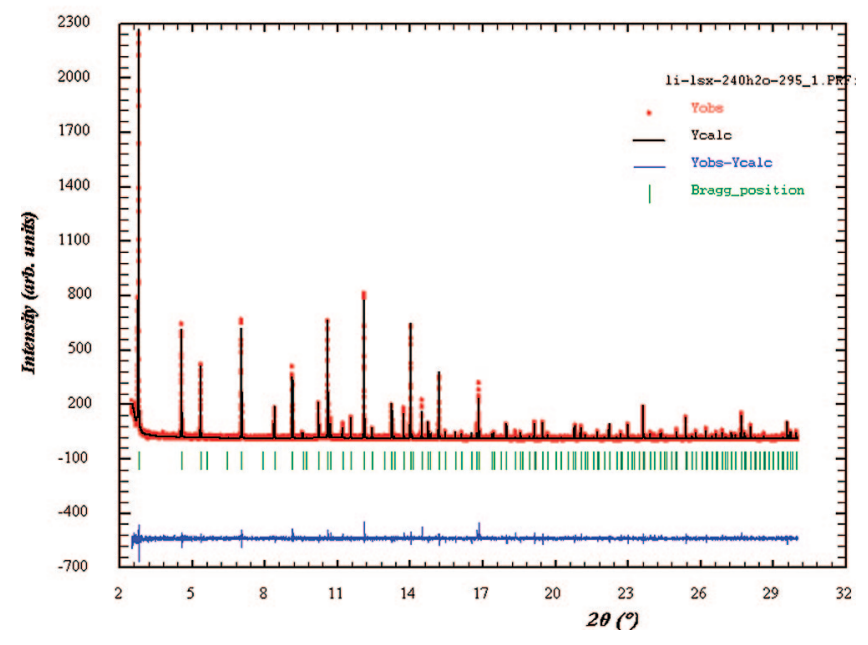

Figure 8. Synchrotron powder pattern and Rietveld plot for the refinement of fully hydrated zeolite Li-LSX $\left(274 \mathrm{H}_{2} \mathrm{O}\right.$ per unit cell).

occupying one of the two possible positions. The $\mathrm{W} 3-\mathrm{O}_{\text {framework }}$ distances with values of $3.2 \AA$ (O1) and 3.23 $\AA$ (O4) are large indicating very weak interactions.

Under the influence of hydration there are even less $\mathrm{Li}^{+}$ cations on site SIII. Only $8 \mathrm{Li}^{+}$per unit cell could be detected. The missing $24 \mathrm{Li}^{+}$cations obviously moved to other sites in the structure most likely coordinated by water. Unfortunately, the analysis of the diffraction data did not allow them to be located.

Although $\mathrm{Li}^{+}\left(\mathrm{SI}^{\mathrm{C}}\right)$ and $\mathrm{Li}^{+}\left(\mathrm{SII}^{\mathrm{C}}\right)$, both residing in the center of a $6 \mathrm{MR}$, are crystal chemically very similar, only $\mathrm{Li}^{+}\left(\mathrm{SII}^{\mathrm{C}}\right)$ is coordinated by a water molecule. The observation that even at this relatively high water content no water is present inside the sodalite cage coordinating $\mathrm{Li}^{+}\left(\mathrm{SI}^{\mathrm{C}}\right)$, is probably due to the fact that all 6MR which could serve as an entrance to the cage are blocked by $\mathrm{Li}^{+}$cations being tightly bound to the oxygen atoms of the ring.

3.2. Rietveld Analysis of Fully Hydrated Li-LSX from Synchrotron Powder Data. The structure of the fully hydrated sample was also refined based on space group symmetry $F d \overline{3}$. The average $\mathrm{Si}-\mathrm{O}$ and $\mathrm{Al}-\mathrm{O}$ distances are $1.64 \AA$ and $1.71 \AA$, respectively. The Rietveld plot for the refinement of Li-LSX zeolite is shown in Figure 8, and the positional parameters and occupancies are reported in Table 5. As in the neutron diffraction study, the water molecules were represented by oxygen atoms with a high displacement parameter. The scattering contribution of the hydrogen atoms is included in the site occupation factors of these oxygen atoms. This is meaningful because of the high displacement parameter of the oxygen atoms and the poor contribution of the hydrogen. Of the 96 lithium cations, 64 could be located occupying the known sites $\mathrm{SII}^{\mathrm{C}}$ and $\mathrm{SI}^{\mathrm{C}}$ with exactly 32 lithium atoms per site. The remaining $32 \mathrm{Li}$ cations were not localized, and no Li cation remained at site SIII. In the fully hydrated sample three new water positions $\mathrm{W} 1, \mathrm{~W} 5$, and W6 were observed, in addition to the water at sites already identified: W2, W3, and W4 (Figure 9). W1 is situated in the sodalite cage close to the cations on $\mathrm{SI}^{\mathrm{C}}$ with a distance of $2.08 \AA$ to the $\mathrm{Li}^{+}$. The water molecules occupying site W1 are positionally highly disordered yielding an electron density distribution of almost a hollow sphere inside the sodalite cage.

Sites W5 and W6 are only interconnected to other water sites and have no contacts to lithium cations or framework atoms. W5 has three bonds to W4 $\left(d_{\mathrm{W} 4-\mathrm{W} 5}=2.96 \AA\right)$ and one bond to $\mathrm{W} 6\left(d_{\mathrm{W} 5-\mathrm{W} 6}=3.04 \AA\right)$. The site $\mathrm{W} 6$ resides in the center of the large cage with four bonds to W5. The sites W4, W5, and W6 make up a 4-connected water network in the center of the super cage (Figure 10) representing a section of the cubic Ice Ic structure. ${ }^{14}$ The geometry of the network demonstrates that this part of the water structure inside LiLSX is obviously mainly dominated by water-water interactions while the arrangement of the molecules at W3, W2, and $\mathrm{W} 1$ is predominantly influenced by water-cation interactions. The relative arrangement of the Ice Ic-type network to the sites W2 and W3 leads to bonds which cannot be described by regular polyhedra. The distance between neighboring, symmetry related water molecules of site W3 now is approximately $2.19 \AA$. Considering the observed occupancy factor it must be concluded that in this case both neighboring molecules are present. According to the structure refinement $274 \mathrm{H}_{2} \mathrm{O}$ molecules per unit cell are included in the pore volume of fully hydrated Li-LSX.

3.3. Forcefield Simulations. 3.3.1. Parameterization of the Lithium Cations. The initial coordinates of the framework atoms and the lithium cations were taken from the final refinement of the neutron diffraction data at low water loading (see Table 2). To test the quality of the CVFF forcefield implemented in Discover3, the $\mathrm{Li}^{+}$positions were optimized. Since the original forcefield parameters yielded too long distances between $\mathrm{Li}$ and $\mathrm{O}$ atoms (Table 7), the Lennard-Jones parameters for $\mathrm{Li}^{+}$were adjusted manually (Table 6). Applying the modified $\mathrm{Li}^{+}$parameters, only the distance $\mathrm{Li}^{+}$(SIII)-O4 shows slight deviation from the experimental value (see Table 7).

3.3.2. Energy of the Attached Single Water Molecule at Different Water Sites. The aim of the calculations was to examine the energy of interaction between a single water molecule at different sites W1-W6 (experimentally refined) and the lithium containing framework $\mathrm{Li}_{96}\left[\mathrm{Si}_{96} \mathrm{Al}_{96} \mathrm{O}_{384}\right]$. The positions of the framework atoms including lithium cations were kept fixed. As a starting point the water molecule on site W6 was used, fixing its oxygen atom in the center of the supercage. The water molecule on site W6 has no direct

(14) Shallcross, F. V.; Carpenter, G. B. J. Chem. Phys. 1957, 26, 782784 
Table 5. Synchrotron Diffraction Refinement at $303 \mathrm{~K}^{a}$

\begin{tabular}{|c|c|c|c|c|c|c|c|}
\hline atom & $x$ & $y$ & $z$ & SOF & Biso & multiplicity of site & number of atoms/unit cell \\
\hline Sil & $-0.0486(4)$ & $0.1250(4)$ & $0.0355(4)$ & 1.00 & 1.4 & 96 & 96 \\
\hline Al1 & $-0.0515(4)$ & $0.0373(4)$ & $0.1227(4)$ & 1.00 & 1.4 & 96 & 96 \\
\hline $\mathrm{O} 1$ & $-0.1033(9)$ & $-0.0033(14)$ & $0.1025(8)$ & 1.00 & 2.8 & 96 & 96 \\
\hline $\mathrm{O} 3$ & $-0.0251(7)$ & $0.0724(6)$ & $0.0693(6)$ & 1.00 & 2.8 & 96 & 96 \\
\hline $\mathrm{O} 4$ & $-0.0740(6)$ & $0.0792(6)$ & $0.1732(6)$ & 1.00 & 2.8 & 96 & 96 \\
\hline $\mathrm{Li}^{+}\left(\mathrm{SI}^{\mathrm{C}}\right)$ & $0.041(2)$ & $0.041(2)$ & $0.041(2)$ & 0.33333 & 2.6 & 32 & 32 \\
\hline $\mathrm{Li}^{+}\left(\mathrm{SII}^{\mathrm{C}}\right)$ & $0.232(2)$ & $0.232(2)$ & $0.232(2)$ & 0.33333 & 2.6 & 32 & 32 \\
\hline W2 & $0.2750(8)$ & $0.2750(8)$ & $0.2750(8)$ & $0.42(2)$ & 10 & 32 & $32(2)$ \\
\hline W1 & $0.090(2)$ & $0.090(2)$ & $0.090(2)$ & $0.24(1)$ & 30 & 32 & $18(1)$ \\
\hline W5 & $0.446(2)$ & $0.446(2)$ & $0.446(2)$ & $0.35(3)$ & 30 & 32 & $27(1)$ \\
\hline W6 & 0.625 & 0.625 & 0.625 & $0.12(1)$ & 30 & 8 & $9(1)$ \\
\hline
\end{tabular}

${ }^{a}$ Optimized atomic coordinates, site occupancy factors, displacement parameters, multiplicity of sites, and number of atoms in occupied site per unit cell for Li-LSX with loading of $270 \mathrm{H}_{2} \mathrm{O}$. Water molecules (W) are represented by oxygen atoms during the refinement. For the calculation of the number of water molecules per unit cell the scattering contribution of the hydrogen atoms is taken into account: Number of water molecules per unit cell $=\mathrm{SOF} \times 96 \times 10 \mathrm{e}^{-} / 8 \mathrm{e}^{-}$.

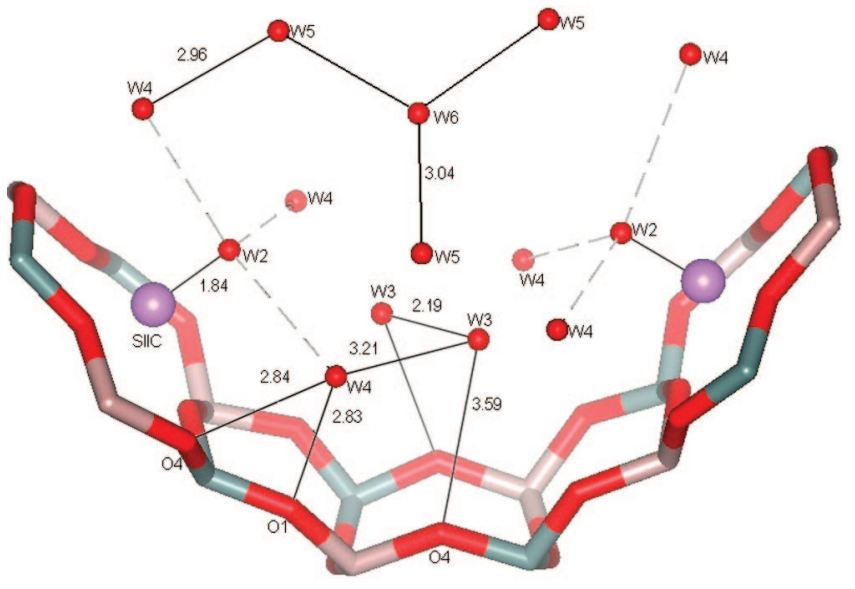

Figure 9. Water network in the fully hydrated Li-LSX.

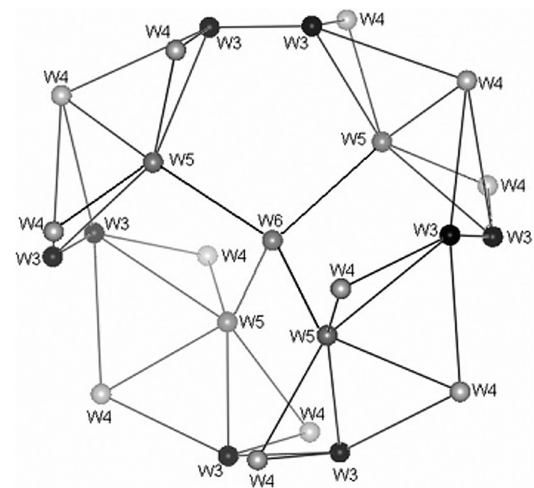

Figure 10. Water sites W4, W5, and W6 make up a water network in the super cage representing a section of the cubic Ice Ic structure.

interactions since all distances between W6 and other atoms are larger than $6 \AA$. This gives a system of two separate units: water at W6 and the lithium containing framework. The resulting energy after optimization is used as a reference value and was set to $E=0$. A single water molecule was put in the close vicinity of sites W1, W2, W3, "Li ${ }^{+}$-free"W3, W4, or W5. This was done in several attempts. Subsequently the particular water position was optimized.

It turned out that water molecules on sites W4 and W5 are not stable but are shifted such to coincide approximately with sites W3 and W2. This is in line with results of the structure analysis which showed that sites W5 and W4 are only occupied if water molecules on sites W3, W2 are already present. The
Table 6. Summary of the Potential Parameters Used To Represent the Host-Guest Interaction

\begin{tabular}{cclc}
\hline & & \multicolumn{2}{c}{ nonbonding parameters } \\
\cline { 3 - 4 } element & charge & $r_{i}^{a}(\AA)$ & $\varepsilon_{i}\left(\mathrm{kcal} \mathrm{mol}^{-1}\right)$ \\
\hline $\mathrm{Si}$ & 2.05 & 4.54983 & 0.0400184 \\
$\mathrm{Al}$ & 1.75 & 4.54983 & 0.0400184 \\
$\mathrm{O}$ & -1.2 & 3.21 & 0.228 \\
$\mathrm{Li}$ & 1 & $1.6^{a}$ & $4.731^{a}$ \\
$\mathrm{O}^{(\mathrm{H} 2 \mathrm{O})}$ & -0.82 & 3.21 & 0.228 \\
$\mathrm{H}$ & 0.41 & 2.75 & 0.038 \\
${ }^{a}$ & &
\end{tabular}

highest energy of interaction was calculated for site W3 being attached to $\mathrm{Li}^{+}$(SIII): $E=17 \mathrm{kcal} / \mathrm{mol}$. The energies calculated for a water molecule on sites W1, W2, and "Li-free"-W3 are nearly identical with approximately $7 \mathrm{kcal} / \mathrm{mol}$.

The calculations showed that the energetically most attractive site in the structure is indeed site W3 followed by the sites W1, W2, and "Li-free"-W3.

3.3.3. Determination of Water Positions in Li-LSX. To determine all "stable" water positions in the unit cell the experimental Li-LSX structure was fully dehydrated and all $\mathrm{Li}$ positions were optimized. At first only one single water molecule was docked 10.000 times into the lattice using the Monte Carlo docking procedure of InsightII ( $E=10 \mathrm{kcal} /$ mol). After optimization of the lithium positions together with the docked water molecule the 100 structures with lowest energies were analyzed in more detail. While the $\mathrm{Li}$ cations are located at three different sites $\mathrm{SI}^{\mathrm{C}}, \mathrm{SII}^{\mathrm{C}}$, and SIII), the water molecule can occupy five different positions: in about $10 \%$ of the structures it is close to Li cations at site $\mathrm{SI}^{\mathrm{C}}$ and $\mathrm{SII}^{\mathrm{C}}$ (site W1 and W2). The majority is close to the Li cation at site SIII (site W3). Due to the partial occupation of site SIII by $\mathrm{Li}^{+}$water molecules also occupy the "vacant" $\mathrm{Li}^{+}$(SIII) position $\left(\mathrm{O}_{\mathrm{H} 2 \mathrm{O}}-\mathrm{O} 4=2.99, \mathrm{O}_{\mathrm{H} 2 \mathrm{O}}-\mathrm{O} 1=4.22 \AA\right)$.

Subsequently, additional water molecules were docked into the unit cell using the same docking procedure and energy thresholds ranging from $E=6.8 \mathrm{kcal} / \mathrm{mol}$ to $E=-5.5 \mathrm{kcal} /$ mol. Due to the complexity of the problem, docking was limited to one resulting structure. After having added 100, 200, 210, 220, and finally 230 water molecules, $\mathrm{Li}^{+}$and water positions were optimized before another attempt was made to dock additional water molecules. Using this energy threshold we were unable to dock more than 230 water 
Table 7. Interatomic Distances between Li and O Atoms As Obtained from Diffraction Experiments and from the Simulation Using Different Forcefield Parameters for $\mathrm{Li}^{+}$

\begin{tabular}{|c|c|c|c|c|c|}
\hline \multirow[b]{2}{*}{ distance in $\AA$} & \multicolumn{3}{|c|}{ experimentally determined (neutron diffraction) $\mathrm{Li}-\mathrm{O}$ distances } & \multicolumn{2}{|c|}{ simulation } \\
\hline & $\mathrm{Li}-\mathrm{LSX} \cdot 8 \mathrm{D}_{2} \mathrm{O}$ this study & dehydrated Li-LSX, Plevert et al. & dehydrated Li-LSX, Feuerstein and Lobo & original cvff & adjusted cvff \\
\hline $\mathrm{Li}^{+}\left(\mathrm{SI}^{\mathrm{C}}\right)-\mathrm{O} 3$ & 1.89 & 1.89 & 1.89 & 2.55 & 1.88 \\
\hline $\mathrm{Li}^{+}\left(\mathrm{SII}^{\mathrm{C}}\right)-\mathrm{O} 2$ & 1.99 & 1.98 & 1.98 & 2.70 & 1.97 \\
\hline
\end{tabular}

molecules into the unit cell of Li-LSX. All newly added water molecules were found to be close to the six water sites W1-W6. Figure 11 shows a comparison of the calculated water distribution with the water sites obtained from the powder diffraction analysis of Li-LSX with a loading of 274 water molecules. The fourth and fifth type of positions is close to the sites W4 and W5 at which the water molecules are inside of the supercage and far away from any framework atom and $\mathrm{Li}$ cation. While most of the calculated water positions agree well with the experimental sites the (experimental) W4 and W5 positions are not exactly reproduced in the calculations.

This is due to energetically weak interactions between water and framework atoms or lithium cations caused by the long distances $\mathrm{W} 4-\mathrm{O}_{\text {framework }}$ of $4.25 \AA$ and $\mathrm{W} 5-\mathrm{O}_{\text {framework }}$ of $5.76 \AA$. Only one water molecule was found at the W6 site.

3.3.4. Mobility of $\mathrm{Li}^{+}$in Site SIII. To study the disorder of $\mathrm{Li}^{+}$at the site SIII we performed molecular dynamics simulations of $\mathrm{Li}-\mathrm{LSX} \cdot 48 \mathrm{H}_{2} \mathrm{O}$. This partially hydrated variant was chosen because of experimental problems in determining the $\mathrm{Li}^{+}$position at site SIII in crystals with higher water loadings. For comparison the same MD simulations were performed with the fully dehydrated $\mathrm{Li}$ LSX. Out of $10 \mathrm{Li}-\mathrm{LSX}$ structures with 48 water molecules docked, the three with the lowest energies were taken as starting structures for three independent MD calculations (NVT ensemble, $25 \mathrm{ps}$ simulation time, $1 \mathrm{fs}$ time step, $T=$ $360 \mathrm{~K}$ as experiment, framework atoms fixed, frames recorded every $250 \mathrm{fs}$ ). After optimization of the nonframework atoms, the maximum and minimum value of the $x$-, $y$-, and $z$-coordinates of each individual $\mathrm{Li}$ cation over all frames was determined. The $\mathrm{Li}$ positions were then sorted according to their crystallographic site $\left(\mathrm{SI}^{\mathrm{C}}, \mathrm{SII}{ }^{\mathrm{C}}, \mathrm{SIII}\right)$, and the minimum and maximum value of the $x$-, $y$-, and $z$-coordinates over all symmetry dependent cations was

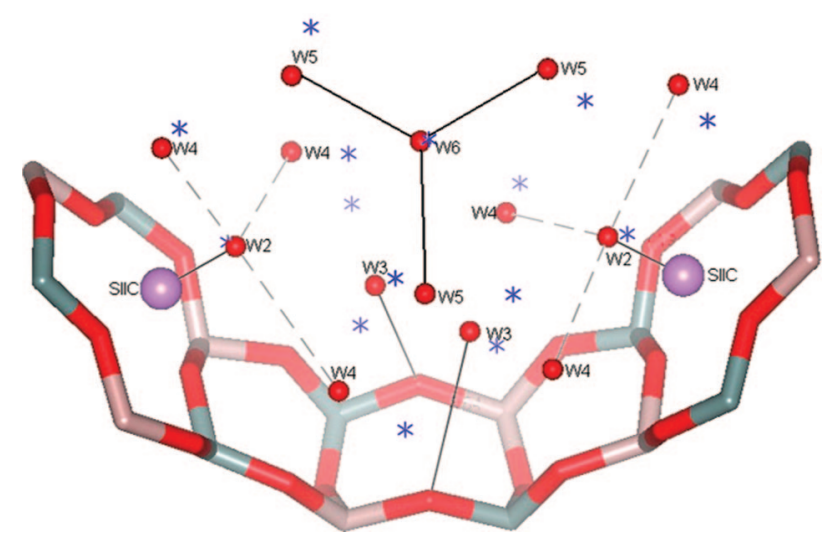

Figure 11. Calculated (asterisks) and experimental water position W2-W6 in fully hydrated Li-LSX.
Table 8. Disordering of Lithium Cations in Fully Dehydrated Li-LSX and at Loading of $48 \mathrm{H}_{2} \mathrm{O}$

\begin{tabular}{lccc}
\hline \multicolumn{1}{c}{ Li-LSX } & $\begin{array}{c}\mathrm{Li}^{+}\left(\mathrm{SI}^{\mathrm{C}}\right) \\
\mathrm{V} 1\left[\AA^{3}\right]\end{array}$ & $\begin{array}{c}\mathrm{Li}^{+}\left(\mathrm{SII}^{\mathrm{C}}\right) \\
\mathrm{V} 2\left[\AA^{3}\right]\end{array}$ & $\begin{array}{c}\mathrm{Li}^{+}(\mathrm{SIII}) \\
\mathrm{V} 3\left[\AA^{3}\right]\end{array}$ \\
\hline dehydrated & 0.078 & 0.083 & 0.195 \\
hydrated $\left(48 \mathrm{H}_{2} \mathrm{O}\right)$ & & & \\
MD run 1 & 0.097 & 0.076 & 1.156 \\
MD run 2 & 0.092 & 0.070 & 1.553 \\
MD run 3 & 0.109 & 0.074 & 2.372
\end{tabular}

calculated. Finally these coordinates were used to describe the volumes $V=\left(x_{\max }-x_{\min }\right)\left(y-y_{\min }\right)\left(z_{\max }-z_{\min }\right)$ which serve as an estimate for the degree of "disorder" of the $\mathrm{Li}$ atoms. The results are listed in Table 8. While the volumes $\mathrm{V} 1$ and V2 remain almost constant when switching from a dehydrated to a partially hydrated system the volume V3 increases by a factor of about 10 . This agrees nicely with the rapid decrease in the experimentally determined occupation number (see Table 2) of $\mathrm{Li}^{+}$(SIII) for higher water loadings while the occupation numbers of $\mathrm{Li}^{+}\left(\mathrm{SI}^{\mathrm{C}}\right)$ and $\mathrm{Li}^{+}\left(\mathrm{SII}^{\mathrm{C}}\right)$ are unaffected (Figure 12).

\section{Conclusions}

In the present work, we have investigated in detail the distribution of $\mathrm{Li}^{+}$cations and water molecules in partially and fully hydrated zeolite Li-LSX. To complement the experimental results which were obtained by neutron and synchrotron powder diffraction methods, forcefield simulation was applied in addition.

The structure analysis shows that among the three observed lithium sites $\left(\mathrm{SI}^{\mathrm{C}}, \mathrm{SII}^{\mathrm{C}}, \mathrm{SIII}\right)$ the sites $\mathrm{SI}^{\mathrm{C}}$ and $\mathrm{SII}^{\mathrm{C}}$ are completely occupied by $\mathrm{Li}^{+}$cations at all stages of hydration. The occupancy of site SIII, however, decreases continuously with increasing water content. The results of molecular dynamics calculations indicate that $\mathrm{Li}^{+}$cations occupying site SIII at low water loadings adopt highly disordered positions in the close vicinity of SIII (named here SIII*) if the Li-LSX material is hydrated (see Figure 12). However, this hypothetical position could not be located from neutron

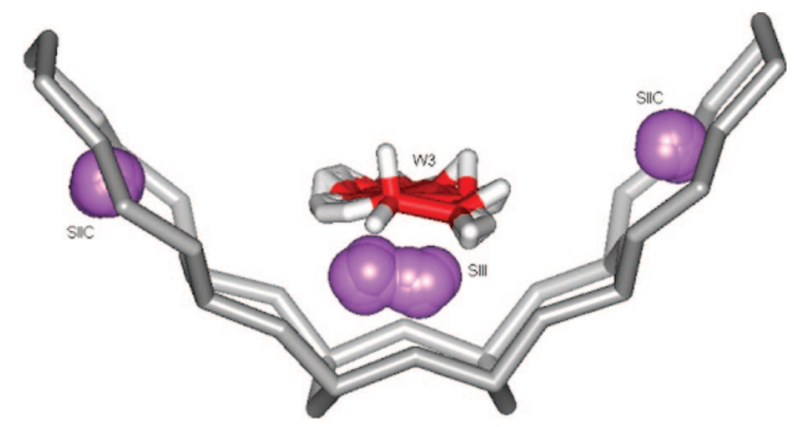

Figure 12. Displacement of lithium cations at sites $\mathrm{SII}^{\mathrm{C}}$ and SIII with loading of 48 water molecules per unit cell as obtained from MD simulation. 
and synchrotron diffraction data because of disorder and low scattering power of lithium. This cation arrangement deviates from the cation distribution in partially hydrated Na-X. The study on $\mathrm{Na}-\mathrm{X}$ is the only investigated structure of a partially hydrated faujasite material so far. ${ }^{15}$ In this material, similar to Li-LSX, the cation sites SI/SI' and SII are nearly completely occupied regardless of the water content of the material. Also the cation population at site SIII decreases with the water loading, but in the structure of $\mathrm{Na}-\mathrm{X}$ an additional cation site SJ (located in the 12-ring) was detected which gets higher cation population with increasing water content.

The very first water molecules which were added to the dehydrated Li-LSX material are positioned at site W3 close to the asymmetrically coordinated $\mathrm{Li}^{+}$(SIII). The cations at SIII are only weakly shielded by framework oxygen atoms and obviously present the energetically most attractive site for the water dipoles. This is in line with the results of the forcefield calculations which gave the highest energy for the interactions of water molecules with $\mathrm{Li}^{+}$at SIII. The assumption that $\mathrm{Li}^{+}$cations which could not be located in the structure analysis are disordered but still located in the close vicinity of SIII (at site SIII') would explain the observation that water at W3 has only very weak interactions with the framework even if no $\mathrm{Li}^{+}$is detected at SIII. We assume that the missing lithium is always in contact with water molecules of site W3.

Increasing the water content led to a higher occupancy of site $\mathrm{W} 3$ and the generation of additional water sites W4 and W2 (coordinating $\left.\mathrm{Li}^{+}\left(\mathrm{SII}^{\mathrm{C}}\right)\right)$. In the structures containing up to 96 water molecules per unit cell only these water sites

(15) Hunger, J.; Beta, I. A.; Böhlig, H.; Ling, C.; Jobic, H.; Hunger, B. J. Phys. Chem. B 2006, 110, 342-353. are observed with increasing occupancies. This is in contrast to the structure of partially hydrated $\mathrm{Na}-\mathrm{X}^{15}$ which possesses water inside of the sodalite cage even at the lowest water loading.

The fully hydrated structure of Li-LSX, finally, possesses three additional water sites: W1 inside the sodalite cage being in contact to $\mathrm{SI}^{\mathrm{C}}$ and sites W5 and W6, both located in the supercage without contact to $\mathrm{Li}^{+}$cations or framework atoms. The water molecules at W4, W5, and W6 make up three-dimensional 4-connected water network inside the super cage resembling the Ice Ic structure.

The position of W4 is not well defined, and no clear statement can be made whether the water molecules at W4 are in contact to framework atoms or lithium cations. It seems possible that the water molecules occupying site W4 interact with the very mobile, disordered $\mathrm{Li}^{+}$. Unfortunately, it proved impossible to distinguish between water molecules at $\mathrm{W} 3$ which are in contact with $\mathrm{Li}^{+}$and those molecules at W3 without contact to lithium cations.

It is interesting to note that the unit cell volume of LiLSX at $200 \mathrm{~K}$ is not affected by the water content (see Table 1) as long as the zeolite is only partially hydrated. The unit cell dimensions are constant within the limits of accuracy. Only the fully hydrated Li-LSX has an expanded structure at $303 \mathrm{~K}$ with a lattice parameter of $a=24.76857$ (4) $\AA .{ }^{16}$

Acknowledgment. This work was performed within BMBF Project No. 035252050. The authors thank the Institute LaueLangevin in Grenoble and Hamburger Synchrotron Radiation for provision of experimental facilities.

\section{CM703654A}

(16) The dataset of fully hydrated Li-LSX recorded at $303 \mathrm{~K}$ was used only to refine the lattice parameter since the presence of impurity phases precluded a complete structure analysis. 